\title{
TECTÔNICA ASSOCIADA À COLOCAÇÃO DE DIQUES ALCALINOS FÉLSICOS E MÁFICOS NEOPROTEROZÓICOS NA ZONA DE CISALHAMENTO DE ITABUNA-ITAJÚ DO COLÔNIA, BAHIA, BRASIL.
}

\author{
LUIZ CÉSAR CORRÊA GOMES $* * * *$, ELSON PAIVA DE OLIVEIRA*,JOHILDO FIGUEIREDO SALOMÃO BARBOSA*** \& \\ PAULOCÉSAR FERNANDES DA SILVA**
}

\begin{abstract}
TECTONIC ASSOCIATED TO EMPLACEMENT OF NEOPROTEROZOIC ALKALINE MAFIC AND FELSIC DYKES IN THE ITABUNA-ITAJU DO COLONIA SHEAR ZONE, BAHIA, BRAZIL The Itabuna-Itaju do Colonia Shear Zone-IICSZ is located in SSE of the Bahia State, Brazil, in the eastern border of the Sao Francisco Craton, near the Brasiliano Marginal Fold Belt of Aracuaf. The IICSZ is oriented $\mathrm{N} 45^{\circ}$ and affects an area of about $4500 \mathrm{~km}$. On its southwestern geographic prolongation it is cut by another shear zone oriented $\mathrm{N} 130^{\circ}$, the Potiragua Shear Zone.

In the IICSZ there are three groups of sheet-like bodies with different characteristics: (i) a Paleoproterozoic (@2.0 Ga-old) amphibolite dyke group, (ii) a Meso-Neoproterozoic (1.0 Ga-old) tholeiitic mafic dyke swarm and (iii) a Neoproterozoic (0.65-0.45 Ga-old) alkaline felsic and mafic dyke swarm of the Itabuna-Itaju do Colônia Province geologically associated with the Alkaline Province of the South of the Bahia and with the IICSZ.

Herein it was applied three different methods to understanding the IICSZ dynamic evolution: (i) comparison among real structural lineament and hypothetical similar patterns obtained through geometric modeling; (ii) structural field data and (iii) field measurements of alkaline dyke emplacement plan.

The result showed that the tectonic history of IICSZ started with a sinistral transcurrent movement, result of a N-S compressive motion, followed by dextral-sinistral transcurrent oscillations and ended with a dextral phase, as a result of E-W compression.

Besides these facts, field observations reveal that the felsic fissural alkaline magmatism was a little older than the mafic one. One the other hand, the fact that the felsic dykes were only mildly affected by the sinistral wrench movement implies a late-tectonic emplacement and a maximum of magmatic volume emplacement during the dextral transcurrent activity.
\end{abstract}

Keywords: Geotectonic, dyke emplacement, shear zones and alkaline rocks

RESUMO A Zona de Cisalhamento de Itabuna-Itaju do Colônia-ZCIIC encontra-se localizada no SSE do estado da Bahia, Brasil, dentro da borda leste do Cráton do São Francisco e próxima à Faixa Marginal de Dobramentos brasilianos Araçuá. Apresenta uma orientacão N45 e afeta uma área em torno de $4500 \mathrm{~km}$. A sua extremidade S W é cortada por outra zona de cisalhamento orientada N140 ${ }^{\circ}$, a Zona de Cisalhamento de Potiraguá

Dentro da ZCIIC podem ser encontrados três grupos de rochas tabulares com características peculiares: (i) um grupo de diques anfibolíticos paleoproterozóicos; (ii) um enxame de diques tholeiíticos de idades próximas a $1.0 \mathrm{Ga}$ e (iii) um enxame de diques alcalinos félsicos e máficos neoproterozóicos, 0.65-0.45 Ga, da ProvínciaFiloniana de Itabuna-Itaju do Colónia, intimamente associados à Província Alcalina do Sul da Bahia e à própria ZCIIC.

Para se estabelecer a evolução dinâmica desta zona de cisalhamento, foram utilizados três tipos de metodologias de análise: (i) comparação dos lineamentos foto-interpretados com padrões similares hipotéticos obtidos por modelagem geométrica, (ii) dados estruturais obtidos no campo e (iii) controle dos planos de colocação dos diques alcalinos cronocorrelatos.

Como resultado disto pôde ser observado que a história tectônica da ZCIIC comecou com uma transcorrência sinistrai, resultado de uma compressão próxima à N-S, que foi seguida por uma fase de oscilação dextral-sinistral e finalizada por uma fase francamente dextral, resultado de uma compressão próxima à E-W.

Além disto observações de campo levam a crer que o magmatismo fissural alcalino félsico foi ligeiramente mais antigo que o máfico, porém o fato de que os diques félsicos se encontram pouco afetados pela dinâmica sinistrai leva a crer que estes filões foram colocados em uma fase tardi-tectônica e que o ápice do magmatismo fissural ocorreu durante a fase dextral.

Palavras-chave: Geotectônica, colocação de diques, zonas de cisalhamento e rochas alcalinas.

INTRODUÇÃO Existem inúmeros trabalhos publicados sobre a relação entre enxames de diques e ambientes tectônicos (Halls 1982, Halls \& Fahrig 1987, Parker et ai. 1990, Baer \& Heimann 1995) sendo notável a associação observada entre sistemas radiais e plumas mantélicas (p.ex.: Oliveira et al. 1990, Hill 1991, Ernst 1995). As relacões entre enxames de diques e zonas de cisalhamento, por outro lado, parecem ser um pouco mais obscuras.

Durante vários anos foram estudados enxames de diques máficos toleíiticos e alcalinos no estado da Bahia, com idades que variam desde $\geq 2.1$ Ga até $0.2 \mathrm{Ga}$ (Oliveira \& Montes 1984, Sial et al. 1987, Corrêa Gomes et al. 1988, Tanner de Oliveira 1989, Corrêa Gomes 1992, Oliveira \& Knauer 1993, Teixeira 1993, Corrêa Gomes et al. 1996). De maneira geral em vários destes casos a distribuição dos filões aparece controlada e compartimentada por zonas de cisalhamento das mais variadas idades.

Esta constatação tornou praticamente obrigatória a utilização de corpos tabulares como ferramenta alternativa de análise estrutural, possibilitando com isto a reconstrução dos eventos tectônicos que produziram uma determinada zona de cisalhamento.

Um bom exemplo deste tipo de situação pode ser encontrado no sudeste do estado da Bahia, dentro do Cinturão granulítico de Itabuna, (Fig. 1), onde aparecem dois elementos geológicos de grande expressão regional: (i) a Zona de Cisalhamento Itabuna-Itaju do Colónia (ZCIIC), abrangendo uma área superior a $4500 \mathrm{~km}^{2}$ e que serve de alojamento para um enxame de diques máficos e félsicos alcalinos (ii) a Província Filoniana de Itabuna-Itaju do Colônia (PIIC).

A ZCIIC representa o resultado da atuação de um regime deformacional predominantemente frágil a frágil-dúctil, possuindo uma orien- tacão $\mathrm{N}^{\circ} 5^{\circ}$. Suas dimensões, $150 \mathrm{~km}$ de comprimento médio e largura em torno de $30 \mathrm{~km}$, refletem a importância da tectônica de ruptura do Ciclo Geotectônico Brasiliano em regiões cratônicas. Além disto, a sua proximidade da Faixa de Dobramento Araçuaí pode possibilitar o entendimento do jogo de tensões atuante neste local dentro do Cráton do São Francisco.

A ZCIIC apresenta como último movimento registrado uma transcorrência dextral, possuindo íntimas relacões com as suítes anorogênicas alcalinas de Itabuna, Itaju do Colónia e Potiraguá, pertencentes à Província Alcalina do Sul da Bahia. É cortada na sua porção SW pela Zona de Cisalhamento de Potiraguá (ZCP), de orientação N140 e cujos traços se estendem até a Chapada Diamantina, no centro do estado da Bahia.

Os principais objetivos deste trabalho serão: (i) analisar estruturalmente os conjuntos de diques aflorantes dentro da área de influência geográfica da ZCIIC; (ii) estabelecer a estratigrafia filoniana observada nas relações de corte entre as gerações de diques; (iii) estabelecer as relações tectônicas existentes entre a colocação dos filões e o regime de deformação crustal contemporâneo.

GEOLOGIA REGIONAL Os principais litotipos afetados pela ZCIIC são granulitos paleoproterozóicos $(2.4 \mathrm{Ga}-2.0 \mathrm{Ga})$, pertencentes ao Cinturão Itabuna (Barbosa \& Dominguez 1996). Estas rochas são resultado de uma mélange tectônica, que superpõe três suítes de características geoquímicas distintas, de $\mathrm{E}$ para $\mathrm{W}$, tholeiítica, calcioalcalina e shoshonítica (Barbosa 1986, Figueiredo 1989, Figueiredo \& Barbosa 1993, Barbosa \& Dominguez 1996) principalmente modeladas por, pelo menos, duas fases regionais mais importantes atribuídas ao Ciclo Geotectônico Transamazônico (Gomes et al. 1991, Loureiro

* Instituto de Geociências, Universidade Estadual de Campinas, Caixa Postal- 6152, 13.083-970, FAX- (019) 239-1562, Campinas, Brasil. e-mail:gomes@ige.unicamp.br

** Instituto de Geocências, Universidade Federal da Bahia, 40.170-290, PABX (071)247-2566, Salvador, Brasil.

*** Departamento de Geografia, Universidade Católica do Salvador, Campus da Federação, 40.000-000, tel.(071)247-1233, ramal 18, Salvador, Brasil. 
1991, Padilha \& Melo 1991, Padilha 1992, Barbosa 1996, Sabaté 1996): (i) a primeira fase estaria relacionada aos cisalhamentos reversos de moderado ângulo para $\mathrm{E}$, que impuseram movimentação tectônica de blocos de E para W e que posteriormente foi afetada por, (ii) uma segunda fase que teria sido marcada por transcorrências sinistrais, como reflexo de uma compressão submeridiana e que registrou a sua presença na forma de lineações penetrativas sub-horizontais. Ambas fases ocorreram em níveis crustais profundos compatíveis com a fácies granulito. Como resultado desta intensa deformação, praticamente todo o Cinturão Itabuna apresenta foliações orientadas próximo à N10 e com mergulho subvertical para E.

Após a evolução do Paleoproterozóico estes terrenos granulíticos passaram por um período de baixa atividade deformacional durante o Mesoproterozóico, só voltando a ser perturbados tectonicamente durante a transição Meso-Neoproterozóico e no Neoproterozóico por cisalhamentos reversos e transcorrentes, associados à formação da bacia sedimentar do Rio Pardo (Pedreira 1979, Karmann 1987), à colocação de vários plutões anorogênicos alcalinos da Província Alcalina do Sul da Bahia (Fujimori 1967, Silva Filho et al. 1974, Lima et al. 1981) e pela movimentacão da Faixa Marginal de Dobramentos brasilianos Araçuaí (Brito Neves et al. 1980, Pedrosa Soares et ai. 1992a,b) localizada imediatamente a sul da ZCIIC.

ASPECTOS GERAIS DA ZONA DE CISALHAMENTO ITABUNA-ITAJU DO COLÔNIA A Zona de Cisalhamento Itabuna-Itaju do Colônia-ZCIIC possui uma área de influência de aproximadamente $4500 \mathrm{~km}^{2}$, com eixo maior de $150 \mathrm{~km}$ se prolongando segundo uma direção $\mathrm{N}^{\circ}$ bem marcada (Fig. 2a). A abundância de zonas de fraturamento do tipo Riedel e anti-Riedel, o estilo rúptil da deformação associada e a atuação apenas localizada de deformação

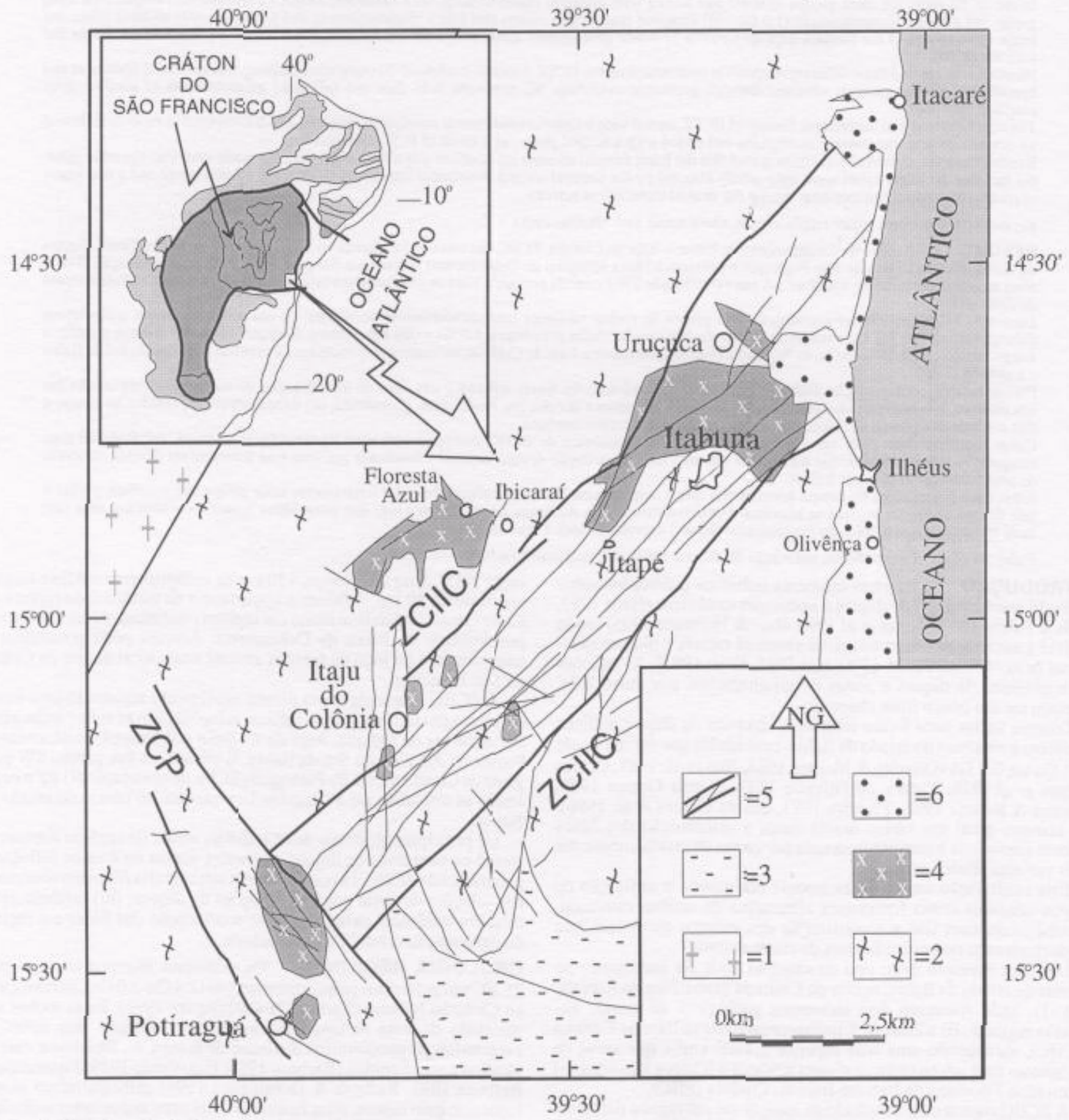

Figura l - Localização da área estudada no Cráton do São Francisco e situação geológica das Zonas de Cisalhamento de Itabuna-Itaju do Colonia (ZCIIC) e Potiraguá (ZCP). 1= Bloco Granulítico de Jequié, paleoproterozóico; 2- Cinturão Granulítico de Itabuna, paleoproterozóico; 3 = Formaçóes Metassedimentares do Grupo Rio Pardo, meso(?)-neoproterozóicas; 4= Sienitos da Província Alcalina do Sul da Bahia, neoproterozoicos; 5= Lineamentos Estruturais da ZCIIC e ZCP e 6=Coberturas sedimentares fanerozóicas (modificado de Barbosa \& Dominguez 1996). 
dúctil conferem à ZCIIC um caráter predominantemente frágil a frágil-dúctil, normalmente ligado à zonas crustais rasas. $\mathrm{O}$ seu último movimento registrado foi o correspondente ao de uma transcorrência dextral (Arcanjo 1993).

$\mathrm{O}$ cisalhamento rúptil afetou indistintamente todo o conjunto de litotipos existentes na região, desde os granulitos paleoproterozóicos do Cinturão Itabuna, até as rochas alcalinas neoproterozóicas das Suítes de Itabuna, Itaju do Colônia e Potiraguá, (Barbosa de Deus et al 1976, Lima et al.1981, Arcanjo \& Oliveira 1991, Arcanjo 1993), de idades compreendidas entre 0.68 Ga e 0.57 Ga (Lima et al 1981, Teixeira 1993, Teixeira et al 1996).

Com base na orientação dos lineamentos estruturais, a ZCIIC pôde ser dividida ainda em três compartimentos estruturais, de NE para SW, (Fig. 2b): (i) zona dos horses, cujas fatias de falhas estão orientadas $\mathrm{N} 20^{\circ}$, (ii) zona principal, marcada pelos longos traços de falhas $\mathrm{N} 45^{\circ}$ e que contem ainda uma sub-zona de horses aproximadamente em seu miolo e (iii) zona de interferência, caracterizada por relações de corte entre os lineamentos $\mathrm{N} 45^{\circ}$ e N140 ${ }^{\circ}$. Esta terceira zona de transição evolui para uma clara situação de transposição da Zona de Cisalhamento de Potiraguá-ZCP, de feições deformacionais localmente mais dúcteis e orientação $\mathrm{N} 140^{\circ}$, sobre a ZCIIC nas proximidades da região de Potiraguá e marca a cronologia relativa entre as duas zonas de cisalhamento.

Principais lineamentos estruturais da Zona de Cisalhamento de Itabuna-Itaju do Colônia A Zona de Cisalhamento Itabuna-Itaju do Colônia-ZCIIC foi investigada estatisticamente através da delimitação dos seus principais lineamentos estruturais (1542 ao todo). Estes foram delineados a partir de imagens de radar e fotos-áereas. Posteriormente suas direções foram medidas e seus comprimentos mensurados para comparação em histogramas de frequência com intervalos de $10^{\circ} \mathrm{em} 10^{\circ}$. Para efeito de simplificação foi feita uma subdivisão em parte NE e parte SW (incluindo também a ZCP), visando facilitar um melhor entendimento do tratamento estatístico dos lineamentos observados (Fig. 2a).

Em seguida serão analisados as frequências e os comprimentos das diferentes famílias lineares delimitadas.

PARTE NORDESTE $\dot{E}$ dominada por lineamentos orientados segundo as direções $\mathrm{N} 20^{\circ}, \mathrm{N} 40^{\circ}$ (predominante) e $\mathrm{N} 110^{\circ}$, como pode ser observado no gráfico de direção x frequência (Fig. 3a).

Quando são computados os comprimentos das linhas frágeis (Fig. 3b) fica nítido que os principais traços são também os correspondentes às direções $\mathrm{N} 40^{\circ}$ (orientação principal da ZCIIC) e N20 família de falhas secundárias, que pode ser visualizada na porção $\mathrm{NE}$ da ZCIIC, correspondente a zona dos horses ou das fatias de falhas. Com isto pode-se chegar a conclusão de que a família $\mathrm{N} 110^{\circ}$, apesar de numerosa ou frequente, possui traços invariavelmente mais curtos que as duas outras famílias.

PARTE SUDOESTE Apresenta características de orientação linear razoavelmente contrastantes com a sub-área anterior, porque os traços mais frequentes ficam concentrados nas direções $\mathrm{N} 30^{\circ}, \mathrm{N} 60^{\circ}, \mathrm{N} 120^{\circ}$ e N140 (Fig. 3c). Mais uma vez o procedimento que melhor denuncia a tendência de arranjo geométrico das linhas frágeis da área está no lançamento comparativo frequência de direção e comprimento (Fig. 3d) que destaca as orientações $\mathrm{N} 30^{\circ}$ e $\mathrm{N} 60^{\circ}$, e dá ênfase a importante família de planos $\mathrm{N} 140^{\circ}$, correspondente aos traços da zona de interferência e da própria Zona de Cisalhamento de Potiraguá.

ÁREA TOTAL Com este tratamento estatístico ficou mais clara a separação das principais orientações das falhas e fraturas de toda área de influência da ZCIIC, segundo as direções $\mathrm{N} 40^{\circ}$, que representa a direção principal da zona de cisalhamento, $\mathrm{N} 140^{\circ}$, direção da ZCP, e as orientações secundárias em baixo ângulo com a ZCIIC N20 e N60 que serão tratados mais a frente (Figs. 3e e 3f).

Modelagem Geométrica -Transcorrências Sinistral $x$ Dextral na Zona de Cisalhameto de Itabuna-ltaju do Colónia Segundo Arcanjo (1993), o movimento dominante das grandes falhas existentes na região de influência da Zona de Cisalhamento de Itabuna-ltaju do Colônia-ZCIIC foi transcorrente dextral, porém o posicionamento de vários dos lineamentos anteriormente discutidos também poderia ser explicado por uma tectônica sinistral. As fatias de falha de orientação N20, vistas na porção NW da ZCIIC por exemplo, poderiam corresponder tanto à falhas do tipo $\mathrm{R}$ de um sistema transcorrente sinistral quanto à falhas do tipo $\mathrm{P}$ de um regime transcorrente dextral.

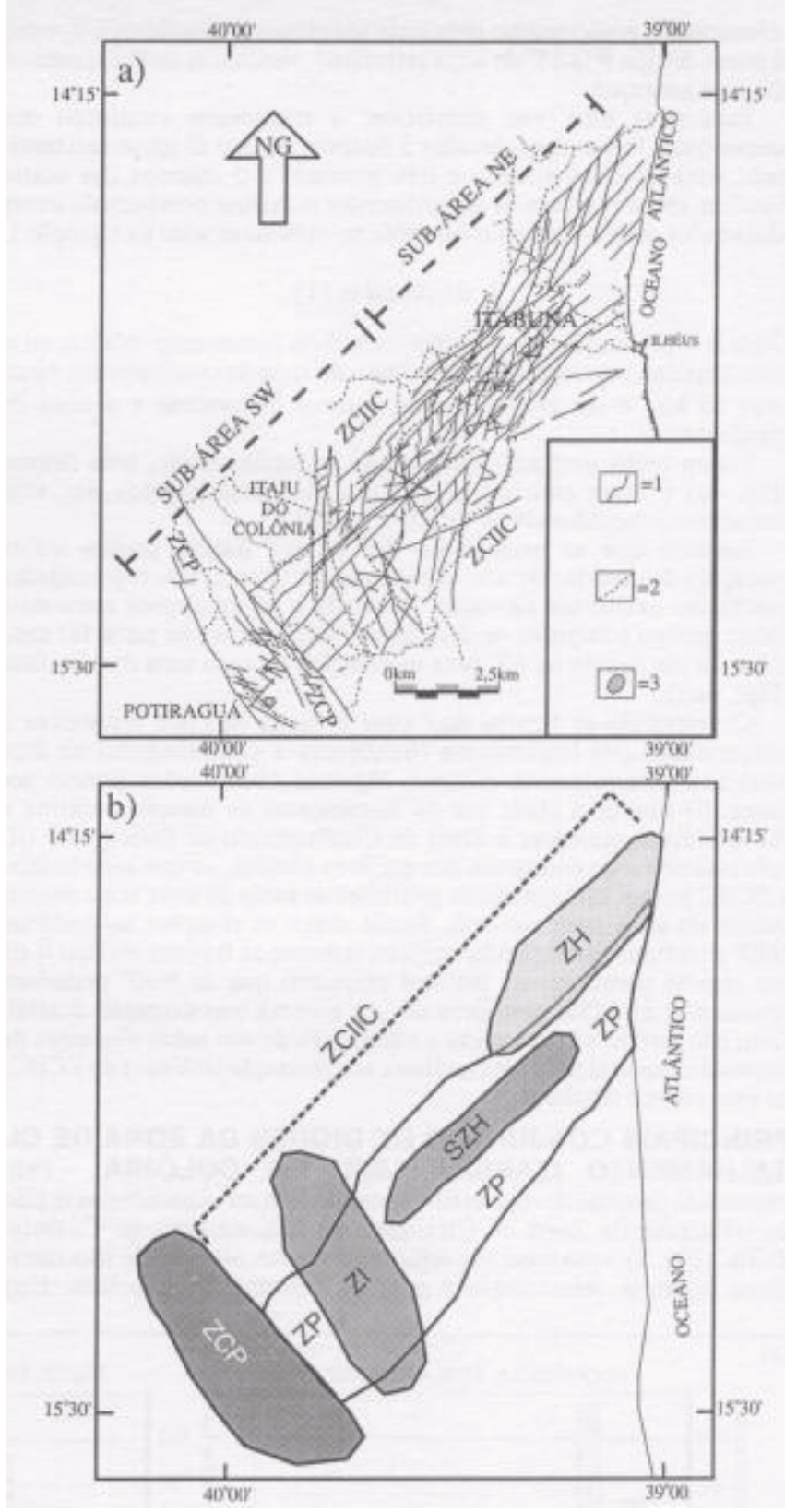

Figura 2 - Principais lineamentos e sub-áreas (a) e compartimentos estruturais (b) das Zonas de Cisalhamento de Itabuna-Itaju do Colónia (ZCIIC) e Potiraguá (ZCP). Em a, 1= Lineamentos Estruturais; 2= Estradas; 3=Cidades. Em b, ZP=Zona de Cisalhamento Principal; $Z I=$ Zona de Interferência; $S Z H=S u b$-Zona de Horses $e$ $\mathrm{ZH}=$ Zona de Horses.

Diante disto surge a questão: teria sido a ZCIIC uma zona de cisalhamento puramente dextral?

Para tentar responder esta pergunta foram montadas e modeladas duas zonas de cisalhamento ideais hipotéticas, uma dextral e outra sinistral, de dimensões semelhantes às da ZCIIC $(150 \mathrm{~km}$ por $30 \mathrm{~km})$, contendo as seguintes famílias, cujos posicionamentos geométricos com relação à zona principal de cisalhamento são bem conhecidos (Cloos 1928, Riedel 1929, Tchalenko 1970, Tchalenko \& Ambraseys 1970, Vialon 1979, Logan \&Teufel 1986, Swanson 1988): (i) fraturas do tipo C, paralelas a zona principal de cisalhamento; (ii) fraturas do tipo $\mathrm{R}$ (a $15^{\circ}$ da zona principal), que representam as sintéticas do sistema de Riedel; (iii) R' (a $70^{\circ}$ da zona principal), representando as antitéticas do sistema de Riedel; iv) fraturas do tipo T extensionais ou tracionais e que tendem a se posicionar de modo paralelo a subparalelo aos planos de tensão $\sigma_{1} \times \sigma_{2} ; \mathrm{v}$ ) fraturas do tipo A, de alívio ou de 
relaxamento, posicionadas próximas aos planos de tensão $\sigma_{2} \mathrm{x} \sigma_{3} \mathrm{e}(\mathrm{vi})$ fraturas do tipo $\mathrm{P}$ (a $15^{\circ}$ da zona principal), simétricas de $\mathrm{R}$ e sintéticas da zona principal.

Para mais uma vez simplificar o tratamento estatístico dos lineamentos foram consideradas 5 fissuras do tipo $\mathrm{C}$ (duas balizando cada zona de cisalhamento e três internas) e 3 internas das outras famílias, todas elas com os comprimentos máximos possíveis de serem alcançados dentro das zonas hipotéticas, obtidos através da equação l:

$$
\mathrm{h}=\operatorname{co} / \operatorname{sen} \sigma(1)
$$

Onde $\mathrm{h}=$ hipotenusa ou o comprimento do lineamento teórico, $\mathrm{co}=$ cateto oposto, correspondente a largura da zona de cisalhamento, neste caso $30 \mathrm{~km}$, e $\sigma=$ menor ângulo entre o lineamento e a zona de cisalhamento.

Foram então montadas duas zonas de cisalhamento, uma dextral (Fig. 4a) e outra sinistral (Fig. 4b) e os comprimentos dos seus lineamentos medidos (Figs. 4c,d).

Sabendo que as orientações dos planos frágeis podem sofrer variações deviatórias devido a, entre outros fatores, heterogeneidades mecânicas existentes na rocha fissurada e as condições tensionais locais do tipo compressiva, distensiva ou transcorrente pura, foi considerado um desvio de $\pm 5^{\circ}$ para as direções de cada uma das famílias (Figs. 4e,f).

Comparando as figuras $4 \mathrm{e}, \mathrm{f}$ com a figura $4 \mathrm{~g}$, que representa a concentração dos lineamentos (frequência x comprimento) na área total real anteriormente descrita, algumas observações podem ser feitas: (i) fíca bem claro que os lineamentos de direção próxima a N140 ${ }^{\circ}$ devem pertencer à Zona de Cisalhamento de Potiraguá e (ii) pela assimetria de contornos dos gráficos obtidos, ao que tudo indica, a ZCIIC possui características geométricas tanto de uma zona dextral quanto de uma zona sinistral. Sendo assim as direções secundárias $\mathrm{N} 20^{\circ}$ poderiam corresponder respectivamente as fraturas do tipo $\mathrm{R}$ de um regime transcorrente sinistral enquanto que as $\mathrm{N} 60^{\circ}$ poderiam representar as falhas sintéticas de um sistema transcorrente dextral. Com isto tornou-se necessária a introdução de um outro elemento de controle estrutural para uma melhor caracterização tectônica da ZCIIC: os seus corpos tabulares.

PRINCIPAIS CONJUNTOS DE DIQUES DA ZONA DE CISALHAMENTO ITABUNA-ITAJU DO COLÔNIA Pelo menos três famílias de rochas filonianas podem ser separadas na região de influência da Zona de Cisalhamento Itabuna-Itaju do ColôniaZCIIC (Fig. 5), com base nas relações de corte, atuação do metamorfismo regional, mineralogia e grau de deformação associada. Elas correspondem às seguintes províncias de diques (Corrêa Gomes et al. 1996):

A Província Metamórfica, composta por diques anfibolíticos, discordantes a subconcordantes com a foliação metamórfica regional próxima à N-S e que encontram-se cisalhados de modo dúctil, principalmente nas bordas, porém ainda preservam os seus formatos tabulares originais. É possível que estes diques estejam ligados aos momentos finais do Evento Transamazônico (2.0 Ga a $1.8 \mathrm{Ga}$ ), correspondentes ao metamorfismo da fácies anfibolito, dentro de uma área dominada por litotipos granulíticos (Barbosa \& Dominguez 1996). Estes representam os diques mais antigos da área e se encontram distribuídos de modo esparso por toda região.

A Província Litorânea, composta por diques de composição tholeiítica, com orientação $\mathrm{N} 90^{\circ}$ a $\mathrm{N} 120^{\circ}$ e idades entre 1.1 Ga e 1.0 $\mathrm{Ga}$ (Ar/Ar, Renné et al. 1990). Apresentam formas retilíneas, angulosas e presença de bordas de resfriamento que atestam o caráter raso de suas colocações, que pode ter variado entre 1.0 e $8.0 \mathrm{~km}$ de profundidade (Corrêa Gomes et al 1988, Tanner de Oliveira 1989, Renné et al 1990, Corrêa Gomes 1992). Marcadores macroscópicos do fluxo magmático (e.g.: enclaves, orientação de cristais prismáticos) indicam um sentido de colocação para estes corpos de Empara W e uma fonte original localizada no Congo, centro-oeste da África (Corrêa Gomes et al. 1996). A província como um todo estaria relacionada a um domeamento litosférico de eixo maior N-S, possivelmente relacionado a uma pluma mantélica (Corrêa Gomes et al. 1988, Renné et al. 1989, Corrêa Gomes 1992, Corrêa Gomes et al. 1995a). Estes filões apresentam-se concentrados principalmente fora da ZCIIC ou na sua porção SW, onde mostram uma intensidade de deformação maior do que a família que vem a seguir.

A Província de Itabuna-Itaju do Colônia, cujos filões félsicos e máficos possuem tendência alcalina (Arcanjo \& Oliveira 1991, Araújo et al 1992, Arcanjo 1993) e idades entre 0.65 Ga e 0.45 Ga (Lima et al 1981) e foram alojados em condições de níveis crustais rasos (Araújo et al 1992. Arcanjo et al 1992, Corrêa Gomes et al 1993, Corrêa Gomes 1995b). Apresentam-se intimamente associados às atividades tectônicas da ZCIIC, sendo afetados por cisalhamentos, principalmente dextrais, com imensidades variáveis.

A principal preocupação das fases de campo deste trabalho foi a de tornar possível a separação das três províncias filonianas, permitindo assim uma melhor filtragem das informações estruturais que serão detalhadas mais a frente.

A separação destes corpos foi facilitada pelas diferenças temporais e deformacionais entre eles visto que: (i) os diques mais antigos são encontrados mais deformados e estão na fácies anfibolito, (ii) os diques

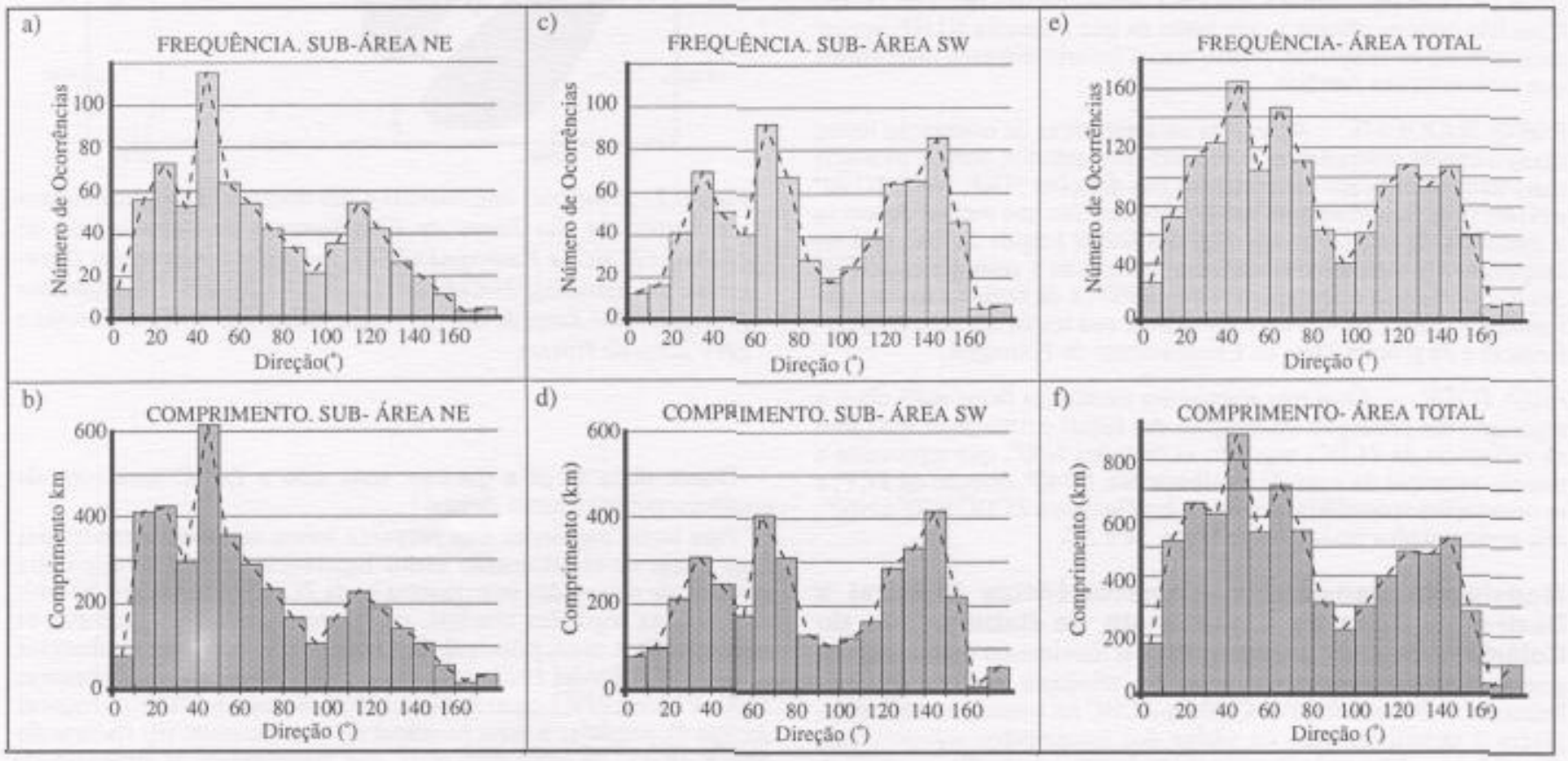

Figura 3 - Gráficos de Frequência X Direção e Comprimento X Direção, para a sub-área NE (a, b), para a sub-área SW (c, d) e para a área total (e, f) da Zona de Cisalhamento de Itabuna-Itaju do Colônia. Na sub-área SW está incluída também a Zona de Cisalhamento de Potiraguá. Para maiores detalhes ver o texto. 


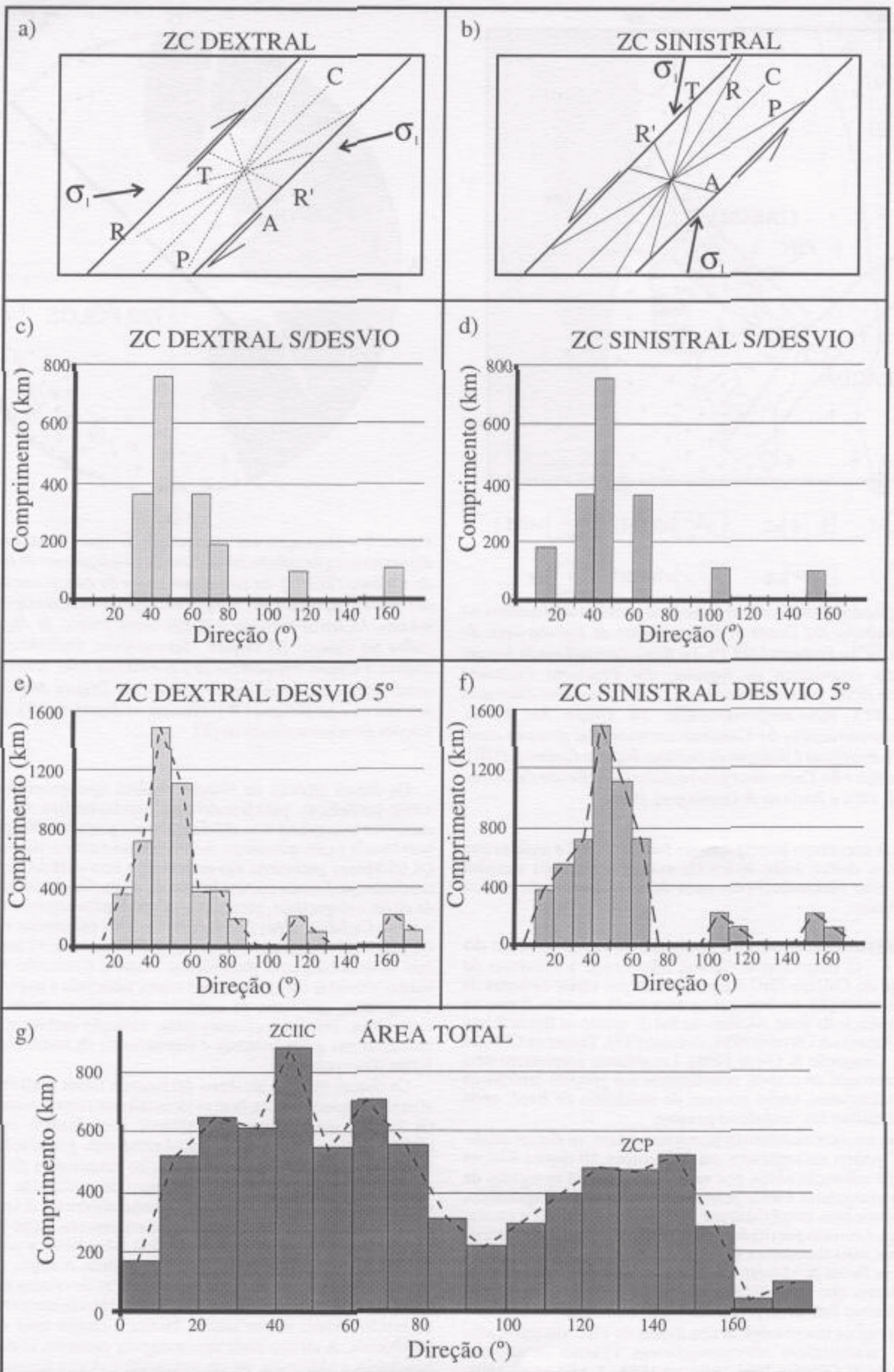

Figura 4 - Representação esquemática de zonas de cisalhamento hipotéticas e de seus principais lineamentos estruturais, transcorrente dextral em a e transcorrente sinistral em b, e gráficos de Direção $x$ Comprimento correspondentes, sem desvio (c, d) e com $\pm 5^{\circ}(e, f)$ de desvio direcional. Para comparação, em g aparece o gráfico de Direção x Comprimento da área total real e os prováveis conjuntos de direções relacionadas às Zonas de Cisalhamento de Itabuna-Itaju do Colônia (ZCIIC) e Potiraguá (ZCP). 


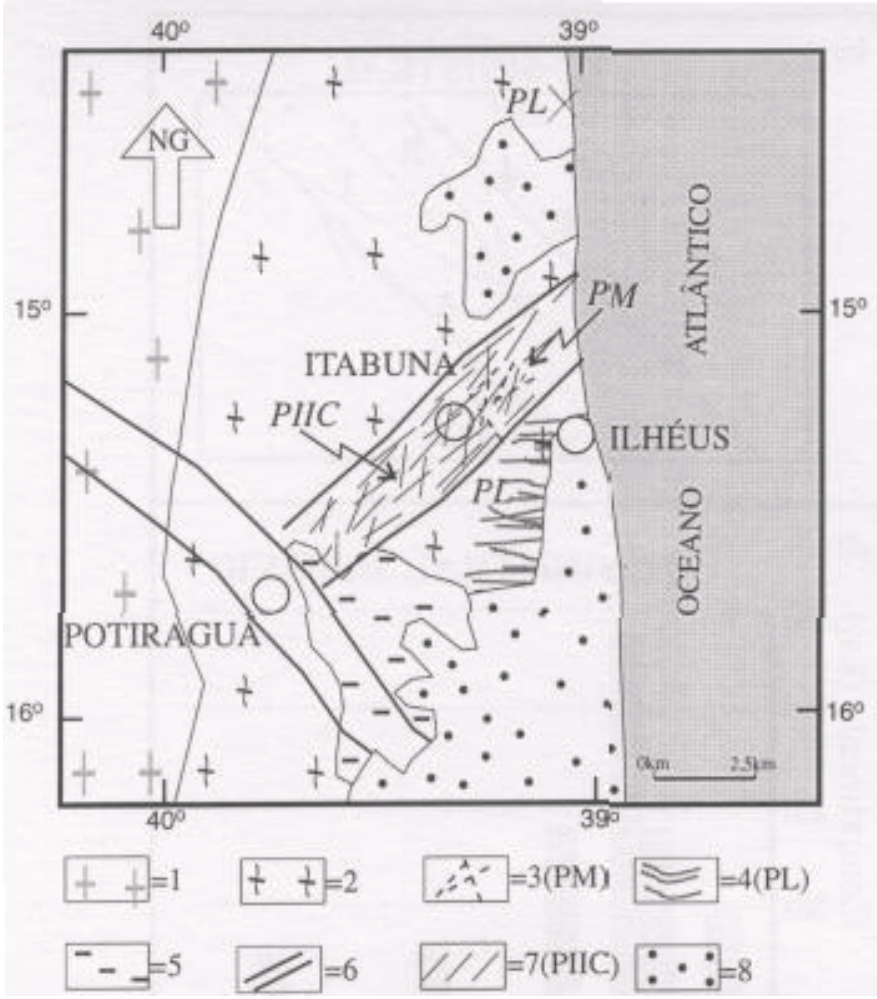

Figura 5 - Quadro geológico e as principais províncias filonianas na área de influência das Zonas de Cisalhamento de Itabuna-Itaju do Colônia (ZCIIC) e Potiraguá (ZCP). 1= Bloco Granulítico de Jequié; $2=$ Cinturão Granulítico de Itabuna; $3=$ Província Filoniana Metamórfica (PM), paleoproterozóica (?); 4= Província Filoniana Litorânea (PL), meso-neoproterozóica; 5= Grupo Rio Pardo, meso( ?)-neoproterozóico; $6=$ Contorno estrutural das zonas de cisalhamento; $7=$ Província Filoniana de Itabuna-Itaju do Colônia (PUC), neoproterozóica e 8= Coberturas fanerozóicas (modificado de Corrêa Gomes et al. 1996 e Barbosa \& Dominguez 1996).

tholeiíticos se encontram principalmente fora da ZCIIC e aqueles que se encontram dentro desta, aparecem normalmente mais afetados (cisalhados e/ou deslocados) pela zona de cisalhamento do que os diques alcalinos.

O magmatismo alcalino da Província de Itabuna-Itaju do Colônia $\mathrm{O}$ magmatismo fissural relacionado à Província de Itabuna-Itaju do Colônia-PIIC é representado por várias centenas de diques de composição alcalina que se encontram situados dentro na zona de ocorrência da Suíte Alcalina do Sul do estado da Bahia (Lima et al. 1981, Arcanjo \& Oliveira 1991, Arcanjo 1993, Tanner de Oliveira 1989,1996, Conceição \& Otero 1996). Localmente apresentam uma maior concentração de corpos, notadamente nas porções centrais da zona de cisalhamento, como no caso do município de Itapé, onde chegam a constituir um verdadeiro enxame.

Com base em suas características macroscópicas, os diques alcalinos da PUC podem ser separados em dois grupos: (i) diques félsicos traquíticos de coloração rósea, por vezes apresentando agregados de fenocristais triangulares a losangulares de K-feldspato e plagioclásio, anfibólio e piroxênio, envolvidos por matriz feldspática fina e escura; este subgrupo é cortado por (ii) diques máficos faneríticos e porfiríticos verde escuros, mais abundantes, podendo aparecer também com menor frequência na forma de vênulas (diqueletes) de, no máximo, $2 \mathrm{~cm}$ de largura e diques que apresentam nas suas porções centrais concentrações de massas sieníticas, platiformes a arredondadas.

As observações macroscópicas dos diques da PUC são reforçadas pelas suas características mineralo-químicas, (Tanner de Oliveira 1989, Arcanjo \& Oliveira 1991, Arcanjo 1993, Araújo et al. 1993 , Tanner de Oliveira 1996), podendo ser classificados nos seguintes tipos: ((i) diques félsicos de filiação alcalina, subdivididos em: quartzo-traquitos, traquitos e fonólitos e (ii) diques máficos de filiação alcalina, subdivididos em basanitos, alcali-basaltos, hawaiitos e mugearitos.

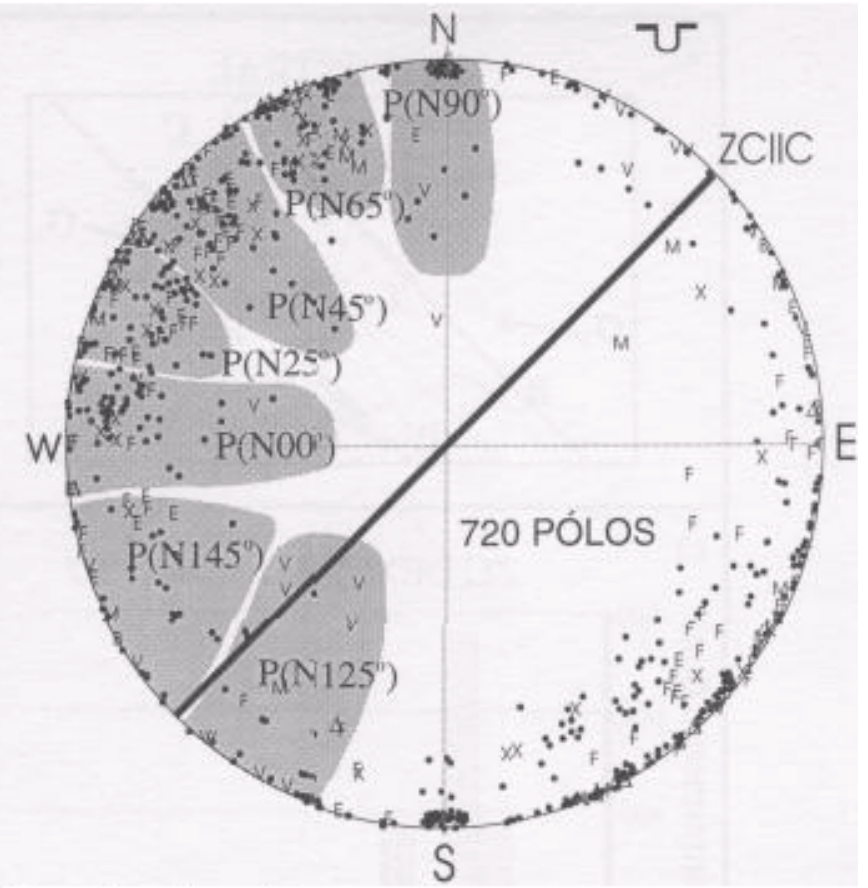

Figura 6 - Marcação em estereorede de igual área dos pólos dos diques na área de influência de Zona de Cisalhamento de Itabuna-Itaju do Colonia (ZCIIC), as principais zonas de concentrações de pólos dos diques, indicadas nos campos em cinza, e os seus respectivos pólos médios. As letras marcam três diferentes grupos de diques identificados no campo: (i) Diques Metamórficos Anfiboliticos (M); (ii) Diques Félsicos Traquíticos (F) e Félsicos com concentrações de alcali-feldspatos triangulares (k.) e (iii) Diques Máficos, comuns faneríticos e porfiríticos (•), Vênulas ou diqueletes (V), com concentrações de massas sieníticas $(X)$.

Os diques félsicos de filiação alcalina apresentam tramas fortemente porfiríticas, panidiomórfica e hipidiomórfica. Os fenocristais euédricos e/ou subédricos são de feldspato potássico, Na-plagioclásio, hornblenda e clinopiroxênio. A matriz é microlítica, por vezes fluidal. Os feldspatos potássicos são ortoclásio e anortoclásio, por vezes microclinizado. Ambos exibem bordas de albita. Os plagioclásios variam de albita a oligoclásio, encontram-se geminados segundo as leis albita e albita-Carlsbad, além de estarem alterados em sericita e moscovita. Os plagioclásios incluem às vezes apatita acicular. O anfibólio é do tipo lamprobolita com pleocroísmo amarelo a castanho escuro, com bordas alteradas em clorita e, por vezes, associada a augita. O opaco é a magnetita, que varia de euédrica até anédrica sendo, por vezes, esquelética. Feições tensionais como extinção ondulante, microquebramento dos grãos minerais e arqueamento da hornblenda, também foram observadas.

Os diques máficos alcalinos apresentam trama porfirítica e matriz afanítica microcristalina, bem evidenciada em corpos menos espessos. Os corpos mais largos são afíricos com textura intergranular, hipidiomórfica e microcristalina. Apresentam granulação fanerítica fina a média. Nos tipos porfiríticos, os fenocristais são euédricos, enquanto nos afíricos os cristais variam de subédricos, a anédricos exceto os opacos, que mostram-se também euédricos. A textura ofítica e, por vezes sub-ofítica, é comumente encontrada. Estes litotipos são constituídos por: plagioclásios, do tipo labradorita a andesina, que exibem boa geminação albita-Carlsbad e albita. A augita é intersticial incluindo opacos, plagioclásio, olivina, além de cristais euédricos de apatita sendo, por vezes, envolvida por hornblenda, em textura de coroa de reação. Altera-se em uralita, biotita e clorita mais opaco e em hornblenda. A olivina pode apresentar cor castanha, alterando-se em bowlingita e iddingsita, ou em serpentina e clorita fibrosa. O opaco é a magnetita, euédrica, subédrica e anédrica, por vezes esquelética, evidenciando cristalização tardia. Nefelina ocorre de forma subédrica e altera-se para minerais de argila. Faixas cataclásticas, impregnadas de óxido de ferro amorfo ou com preenchimento de calcita foram observadas. 

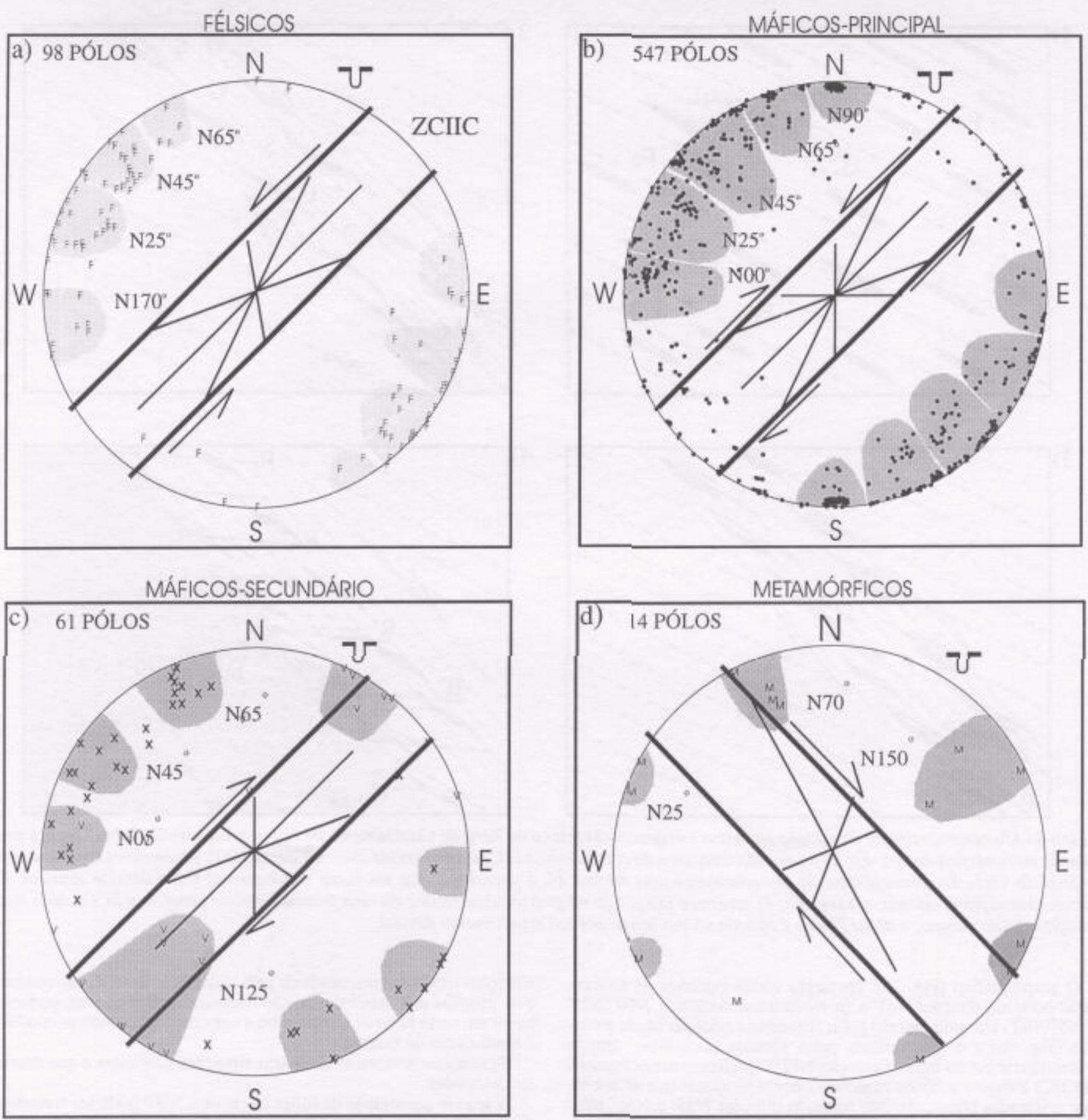

Figura 7 - Separação em rede estéreo gráfica de igual área dos principais grupos de diques encontrados na área de influência da Zona de Cisalhamento de Itabuna-Itaju do Colônia (ZCIIC): a) diques félsicos, b) diques máficos faneríticos e porfiriticos do grupo principal, c) diques máficos com concentrações de massas sieníticas e vênulas do grupo secundário e d) diques metamórficos. Em cada caso aparecem sugeridas as possiveis situações tectônicas responsáveis pela construção das fraturas-conduto de cada grupo e as suas orientações espaciais, muito embora não necessariamente a construção e o preenchimento pelo magma tenham ocorrido ao mesmo tempo.

PRINCIPAIS PLANOS DE COLOCAÇÃO Após a caracterização mineralo-química dos diques da Província de Itabuna-Itaju do ColôniaPIIC, foram tratados os seus planos de colocação. Um total de 524 atitudes planares foram coletadas, em sua grande maioria de diques alcalinos porém, incluindo aqui também alguns planos de diques metamórficos e tholeiíticos para comparação. Estes planos tiveram seus pólos marcados em rede estereográfica de igual área de SchmidtLambert.

Este procedimento permitiu chegar-se as seguintes constatações gerais (Fig. 6): (i) a grande maioria dos corpos tabulares apresenta forte mergulho para SE (mais marcante) e NW; (ii) é possível a visualização de sete núcleos principais de concentrações polares nas seguintes direções: $\mathrm{N} 00^{\circ}, \mathrm{N} 25^{\circ}, \mathrm{N} 45^{\circ}, \mathrm{N} 65^{\circ}, \mathrm{N} 90^{\circ}, \mathrm{N} 125^{\circ}$ e $\mathrm{N} 145^{\circ}$ e (iii) a grande maioria das direções dos planos ficam principalmente restritas ao intervalo de $\mathrm{N}^{\circ}$ a $\mathrm{N} 90^{\circ}$, com grupos mais numerosos nas direções $\mathrm{N} 00^{\circ}, \mathrm{N} 25^{\circ}, \mathrm{N} 45^{\circ}$ e $\mathrm{N} 65^{\circ}$, todas elas praticamente já conhecidas de modo preliminar na análise dos principais lineamentos da Zona de Cisalhamento de Itabuna-Itaju do Colônia-ZCIIC.

É interessante notar que algumas configurações lógicas começam a tomar forma, quando feita uma filtragem mais apurada dos dados, utilizando-se como parâmetros de controle, os pólos dos dois subgrupos da província mais numerosa da área, a PUC.

O grupo félsico (Fig. 7a) apresenta suas principais concentrações de pontos nas direções $\mathrm{N} 25^{\circ}$ e N45 , além de concentrações secundárias em N65 $\mathrm{eN} 170^{\circ}$. 

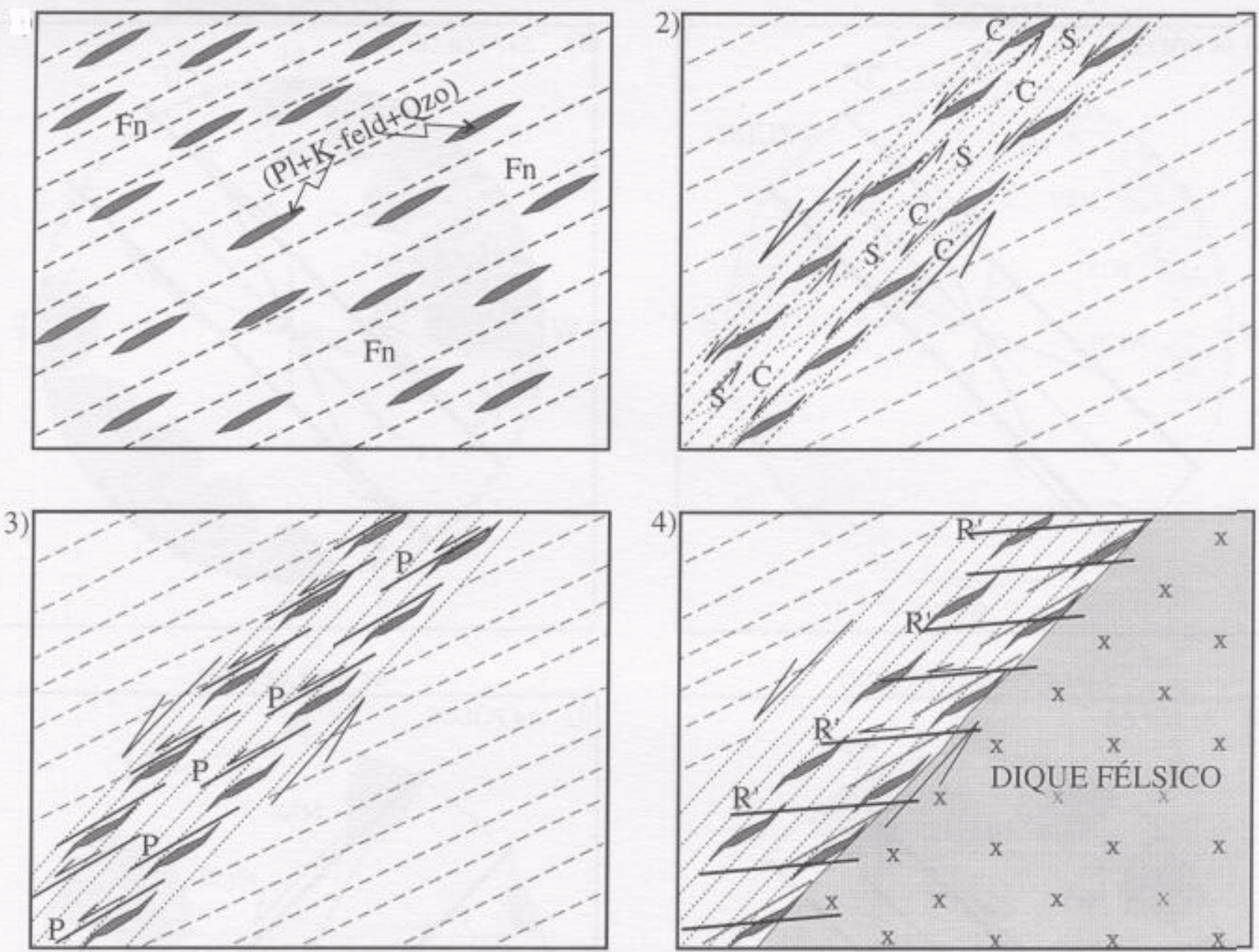

Figura 8 - Afloramento-sintese da relação tectônica x magmatismo félsico na Zona de Cisalhamento de Itabuna-Itaju do Colônia: 1) sobre uma foliação metamórfica antiga $-\mathrm{Fn}$, 2) foi gerada uma zona de cisalhamento (ZC) transcorrente sinistral dúctil N20', possivelmente relacionada ao final do Ciclo Transamazonico, 3) posteriormente esta mesma ZC é parasitada por um outro cisalhamento transcorrente sinistral, de características frágil-dúcteis, em seguida, 4) ocorreu a injeção do magma alcalino félsico em uma fratura-conduto paralela a ZCs e, após total solidificação do magma, o dique félsico é afetado na sua borda por um cisalhamento dextral.

O grupo máfico (Fig. 7b), apresenta várias manchas de concentração polar nas direções $\mathrm{N} 45^{\circ} \mathrm{e}$, de modo quase simétrico, $\mathrm{N} 00^{\circ} \mathrm{N} 25^{\circ}$ e $65^{\circ} / \mathrm{N} 90^{\circ}$. Um grupamento polar secundário pode ser ainda percebido (Fig. 7c) e é representado pelas vênulas (diqueletes) que se concentram segundo uma orientação $\mathrm{N} 125^{\circ}$ (praticamente ortogonais à ZCIIC) e diques máficos contendo massas sieníticas que se encontram orientados principalmente segundo direções $\mathrm{N} 45^{\circ}$ e $\mathrm{N} 65^{\circ}$ além de apresentarem ainda uma concentração menor $\mathrm{N} 05^{\circ}$.

SIGNIFICADO TECTONNICO DOS PLANOS DE COLOCAČ̃O Para os diques do grupo félsico, os posicionamentos observados fazem crer que os seus filôes ocupam fraturas do tipo $\mathrm{C}\left(\mathrm{N} 45^{\circ}\right), \mathrm{R}$ ou $\mathrm{T}\left(\mathrm{N} 25^{\circ}\right)$ e R' $\left(\mathrm{N} 170^{\circ}\right)$ de um regime transcorrente sinistral, sendo que as direções $\mathrm{N} 65^{\circ}$, poderiam representar fraturas do tipo $\mathrm{P}($ ?) do mesmo sistema.

Para o grupo máfico principal da PUC, a direção $\mathrm{N} 45^{\circ}$ continuaria representando fissuras do tipo $\mathrm{C}$, porém as posições $\mathrm{N} 00^{\circ}$ e $\mathrm{N} 25^{\circ}$, por um lado, e $\mathrm{N}^{\circ} 5^{\circ}$ e $\mathrm{N} 90^{\circ}$, por outro, poderiam representar fraturas conjugadas em ângulo muito agudo, respectivamente, de regimes sinistral e dextral. No caso do grupo máfico secundário, correspondente às vênulas e diques contendo massas sieníticas, a orientação $\mathrm{N} 45^{\circ}$ continua representando descontinuidades frágeis do tipo $\mathrm{C}$, enquanto que as $N 65^{\circ}$ corresponderiam às $\mathrm{R}$, as $\mathrm{N} 125^{\circ} \mathrm{R}$ e as $\mathrm{N} 05^{\circ}$ às fraturas de relaxamento (tipo A) de uma ambiência dextral.

Sendo assim, três quadros tectônicos poderiam ser detectados para a ZCIIC, um primeiro transcorrente sinistral associado à colocação dos diques félsicos alcalinos, um segundo relacionado a transcorrências dextral e sinistral, associadas à colocação do grupo máfico principal e o terceiro mais francamente transcorrente dextral, associado à colocação do grupo secundário máfico. É importante salientar-se que as situações tectônicas responsáveis pela construção das fraturas-conduto e as injeções dos magmas não são necessariamente coevas, podendo haver um certo hiato de tempo entre a construção das fraturas-conduto e a colocação do magma.

Existem no entanto ainda outras situações pendentes e que devem ser discutidas.

A grande quantidade de filões orientados $\mathrm{N} 90^{\circ}$ pode ser entendida de duas maneiras: (i) eles fazem parte dos planos produzidos pela ZCIIC e/ou (ii) eles estão relacionados aos eventos geradores dos filões da Província Litorânea, mais antiga, que ocupou o espaço que viria posteriormente a ser afetado pela ZCIIC.

Quanto aos diques metamórficos (Fig. 7d), podem ser vistas pequenas concentrações segundo planos $\mathrm{N} 70^{\circ}, \mathrm{N} 150^{\circ}$ e N25 $5^{\circ}$ o que poderia ser indicativo de um sistema transcorrente dextral orientado $\mathrm{N} 135^{\circ}$ onde o $\sigma_{1}$ regional esteve posicionado segundo uma orientação NNW/SSE. Neste caso, apesar do reduzido número de medidas alguma coerência lógica pode ser observada porque a orientação submeridiana do principal tensor regional é característica da segunda grande fase de deformação do Evento Transamazônico na borda leste do Cráton do São Francisco, de cinemática dominante transcorrente sinistral, (Padilha \& Melo 1991, Padilha 1992, Corrêa Gomes et al. 1996, Sabaté 1996), mas que localmente pode apresentar componentes secundárias dextrais .

TECTONNICA TRANSCORRENTE X COLOCACÃO DO MAGMATISMO FISSURAL ALCALINO Alguns fatos chamam a atenção no controle de campo das estruturas relacionadas a ZCIIC e aos diques alcalinos cronocorrelatos: (i) a atuação da tectônica transcorrente sinistral aparece marcada pela presença de duplexes do tipo C-P 
orientados $\mathrm{N}^{\circ} 5^{\circ}$, de características frágil-dúcteis, de zonas sinistral do tipo R orientadas $\mathrm{N} 25^{\circ}$ e pela presença de diques, com ramificações assimétricas do tipo- $\mathrm{T}, \mathrm{N} 00^{\circ}$, não afetados pela tectônica sinistral, o que indica que eles podem apenas ter se aproveitado de fraturas já construídas; (ii) a atuação transcorrente dextral aparece marcada na presença de fraturas conjugadas R e R' dentro de zonas de cisalhamento $\mathrm{N} 45^{\circ}$, fraturas do tipo- $\mathrm{T}$, orientadas $\mathrm{N} 90^{\circ}$, e principalmente por diques ocupando fraturas $\mathrm{N} 45^{\circ}$ ou com geometrias em degrau construídas sobre estas (preenchimento com tectônica ativa), que denunciam, neste caso, a contemporaneidade do preenchimento com as movimentações das paredes dos condutos.

Além disto, as observações de campo indicam que: (i) a transcorrência sinistral foi anterior à dextral, tendo afetado principalmente os diques félsicos e, mesmo assim, de modo pouco marcado; (ii) os diques félsicos são ligeiramente mais antigos que os máficos, tendo sido ambos afetados pela tectônica dextral.

Um resumo da evolução tectônica da área (Fig. 8) aparece em um afloramento na forma de mútuo paralelismo e ocupações de espaço entre: (i) uma zona de cisalhamento dúctil sinistral $\mathrm{N} 20^{\circ}$, provavelmente transamazônica, marcada pelo achatamento de cristais de plagioclásio+K-feldspato+quartzo e geração de superfícies $\mathrm{S}-\mathrm{C}$ com a foliação principal, (ii) uma zona de cisalhamento frágil-dúctil sinistral, mais recente que a anterior, marcada pelo desenvolvimento de fraturas do tipo-P e (iii) uma zona de cisalhamento frágil dextral, a mais recente de todas, materializada por fraturas do tipo- $\mathrm{R}^{\prime}$, antitéticas sinistrais. Neste caso foi possível notar-se também que as marcas cinemáticas indicam um caminho cada vez mais frágil, das deformações mais antigas para as mais recentes.

Estas três zonas são parasitadas por um dique félsico que foi afetado, neste caso, apenas pela última atividade tectônica frágil dextral. Com isto pôde ser constatado neste local que: (i) apesar dos diques félsicos, por vezes, ocuparem fissuras condizentes com aquelas produzidas por uma transcorrência sinistral eles são no máximo tardi-tectônicos à esta fase e (ii) houve uma inversão do posicionamento dos tensores principais, inicialmente orientados próximos a direção N-S, da fase transcorrente sinistral, e que posteriormente assumiram uma orientação próxima a $\mathrm{E}-\mathrm{W}$, durante a fase transcorrente dextral.

Também é digno de nota a abundância relativa dos diques em campo porque: (i) os diques félsicos são menos abundantes que os máficos, (ii) o grupo máfico principal é mais abundante e apresenta diques normalmente mais espessos que os do grupo máfico secundário. Estes dados podem sugerir que a ZCIIC alternou também condições compressivas com extensivas durante a colocações dos corpos filonianos.

CONCLUSÕES Com a utilização e comparação de vários métodos de análise do tipo: tratamento estatístico de lineamentos estruturais, modelagem geométrica de zonas de cisalhamento, investigação dos planos de colocação de rochas filonianas e observação no campo de marcadores cinemáticos, foi possível perceber-se que a Zona de Cisalhamento de Itabuna-Itaju do Colônia provavelmente passou por três fases de movimentação crustal (Fig. 9): (i) transcorrência sinistral, com o $\sigma_{1}$ regional posicionado próximo a direção N-S; (ii) oscilação tensional com transcorrências alternadas sinistral/dextral e (iii) transcorrência dextral, com o GI regional postado segundo direção próxima a E-W.

Além disto, a rarefação de marcadores da deformação sinistral nos filões, as relações de idade entre os diques félsicos, ligeiramente mais antigos, e os máficos, mais novos e o crescente aumento no volume de magma injetado no sentido do magmatismo máfico alcalino parecem sugerir que: (i) a injeção do magma alcalino félsico ocorreu, no máximo, no final da fase sinistral, indicando que a construção das fraturas e o preenchimento pelo magma não foram necessariamente coevos; (ii) a oscilação entre as fases sinistral e dextral foi rápida sem que tenha havido uma rotação gradativa dos tensores regionais porque isto deixaria marcas da tectônica sinistral inclusive nos diques máficos e (iii) a fase transcorrente sinistral pode ter sido transpressiva e a dextral transtensiva.

Agradecimentos Ao corpo de geólogos da CPRM-BA pelas discussões sobre aspectos de campo da área pesquisada e a Asit Choudhuri, IG-UNICAMP e aos revisores anônimos da RBG pelas sugestões apresentadas que enriqueceram consideravelmente o texto. L.C.C.G. e E.P.O. agradecem também à FAPESP pelo suporte financeiro (Processo 96/3582-3).
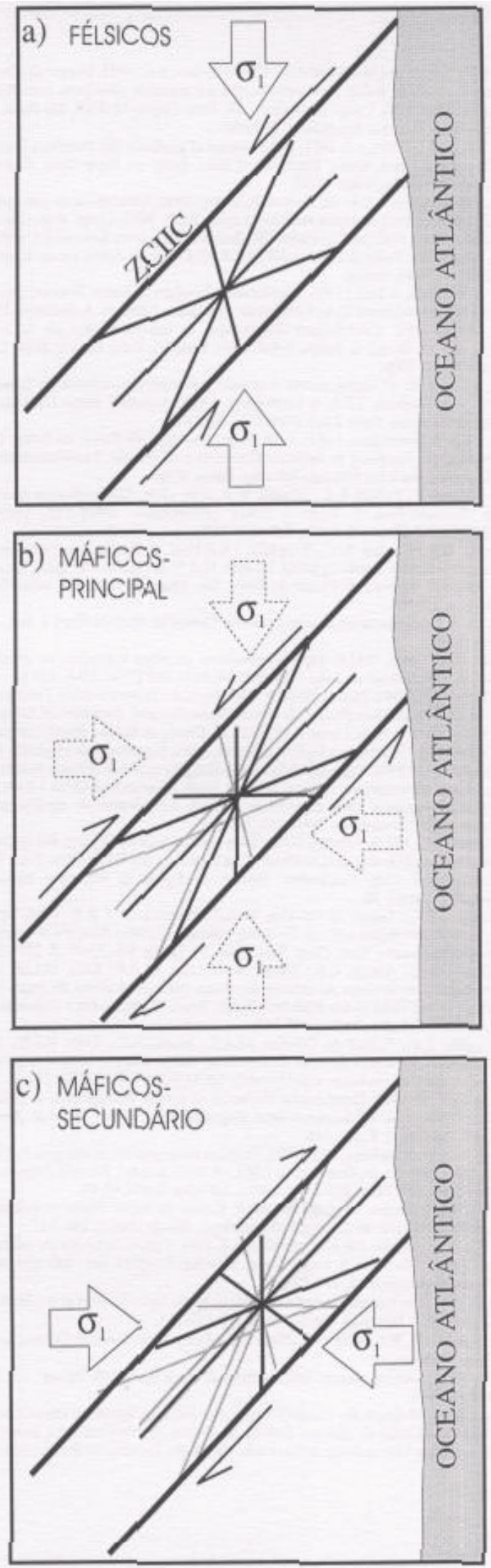

Figura 9 - Provável evolução tectônica associada a construção das fraturas-conduto preenchidas pelo magma alcalino e posicionamentos dos planos das fraturas-conduto e das projeções horizontais dos tensores regionais da Zona de Cisalhamento de Itabuna-Itaju do Colônia: a) transcorrência sinistral; b) oscilação sinistral-dextral e c) transcorrência dextral. 


\section{Referências}

Araújo, C.B.; Tanner de Oliveira, M.A.F.; Corrêa Gomes, L.C. 1992. Diques alcalinos do sul do estado da Bahia. Uma contribuição aos aspectos: geológico, petrológico e geoquímico. SBG, Congr. Brás. Geol., 37, Simp. Diques Máficos, São Paulo, SP., Boletim de Resumos Expandidos, 500-501.

Arcanjo, J.B. A. \& Oliveira, J.E. 1991. Dyke swarms of southeast São Francisco Craton in Itabuna-Itapé area, Bahia, Brazil. In: 77 Inter. Symp. on Mafic Dyke. Excursion Cuide. São Paulo-Brazil, 41-52.

Arcanjo, J.B.A.; Oliveira, J.E. de; Santos, R.A. dos. 1992. Caracterização petrográflca, textura! e química de diques máficos do sul da Bahia. SBG, Congr. Brás. Geol., 37, Simp. Diques Máficos, São Paulo, SP., Boletim de Resumos Expandidos, 498-499.

Arcanjo, J.B.A.1993. Folha de Itabuna SD.24. Y.B.VI, Estado da Bahia, escala 1:100.000 DNPM/CPRM, inédito.

Baer, G. \& Heimann, A. (eds.),1995. Physics and Chemistry of Dykes. Selected papers at III Third International Dyke Conference, Jerusalém, Israel, A. A. Balkema, 339 p.

Barbosa J.F.S. 1986. Contribuition litholoqique et métamorphique de Ia région granulitique du sud de Bahia, Brésil. Univ. Paris VI, Paris, France, Thèse Doct., tome $86-34,300 \mathrm{p}$

Barbosa, J.F.S. 1996. O Embasamento Arqueano e Proterozóieo Inferior do Estado da Bahia. In: Barbosa, J.F.S. \& Dominguez, J.M.L. (coords.), Mapa Geológico do Estado da Bahia. Texto Explicativo, Cap. III, 63-86.

Barbosa, J.F.S. \& Dominguez, J.M.L. 1996. Mapa Geológico do Estado da Bahia. Texto Explicativo. Secretaria da Indústria Comércio e Mineração, Superintendência de Geologia e Recursos Minerais.Salvador, Bahia. 400p.

Barbosa de Deus; P.; Rangel; P.A.; Silveira. W.P. et al. 1976. Projeto Rochas Alcalinas de Itarantim-Fase I. Texto e fichas petrográficas. SME/CPM, Convénio SME/CBPM. Estado da Bahia, Salvador. $160 \mathrm{p}$

Brito Neves, B.B.; Cordani, U.C.; Torquato, J.R.F.1980. Evolução Geocronológica do Precambriano do Estado da Bahia. In: Inda, H.A.V. \& Duarte, F.B. (eds), Geologia e Recursos Minerais do Estado da Bahia. Sec. Minas do Estado da Bahia.Textos Básicos, 1:1-101.

Closs, H. 1928. Experimente zur inneren Tektonik. Central bl. Mineral. Geol. u. Bal., 1928 B:609-621.

Conceição, H. \& Otero, O.M.F. 1996. Magmatismo granítico e alcalino no estado da Bahia. Uma epitome do tema. Convênio SICM/SGM/PPPG/UFBA, 133 p.

Corrêa Gomes, L.C. 1992. Diques Máficos: Uma Reflexão Teórica sobre o Tema e o seu Uso no Entendimento Prático da Geodinâmica Fissural. Exemplos de Salvador e Ilhéus-Olivença, Zona Costeira Atlântica do Estado da Bahia - Brasil. Instituto de Geociências, Universidade Federal da Bahia, Bahia, Dissertação de Mestrado, 196p.

Corrêa Gomes, L.C. 1995a. The mafic dyke swarm along the coastline of Bahia state,Brazil: A attempt of continental breakup between South America and África l .0 Ga ago? Third International Dyke Conference. Session AII-Geodinamic significance of dykes-regional overviews. Jerusalém, Israel, 19.

Corrêa Gomes, L.C. 1995b. Alkaline Dykes firam Itabuna-Itaju de Colônia, Bahia, Brazil: Rheologic and Geody namic Markers of the Evolution of a Brittle Shear Zone. Third International Dyke Conference. Session F- Dykes as estrutural indicators. Jerusalém, Israel, 20.

Corrêa Gomes, L.C.; Tanner de Oliveira, M.A.F.; Bastos Leal, L.R.B. 1988. Feições estruturais dos diques máficos: Relações entre magmatismo fissural e as condiç̃es reológicas do meio. SBG, Cong. Brás. Geol., 35, Belém -PA, Anais,. 5, 2217-2226.

Corrêa Gomes, L.C.; Araújo, C.B.; Tanner de Oliveira, M.A.F.; Cruz, M.J.M. 1993. Mecanismo de intrusão do enxame de diques máficos alcalinos de Itapé. Faixa Atlântica do Cráton do São Francisco, Bahia, Brasil. II Simp. sobre o Cráton do São Francisco, Salvador, Bahia., 115-118.

Corrêa Gomes, L.C.; Tanner de Oliveira, M.A.F.; Motta, A.C.; Cruz, M.J.M. 1996. Províncias dos diques máficos do Estado da Bahia. Mapa, evolução temporal e

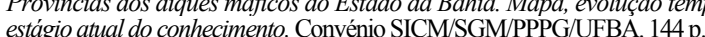

Figueiredo, M.C.H. 1989. Geochemical evolution of eastern Bahia.Brazil: A probably Early-Proterozoic subduction-related magmatic are. Journal of South America Earth Sciences, 2 , $2: 131-145$.

Figueiredo, M.C.H. \& Barbosa, J.S.F. 1993. Terrenos metamórficos de alto grau do Cráton do São Francisco. In: Dominguez, J.M.L. \& Misi, A.(eds), Reunião Preparatória do II Simp. do Cráton do São Francisco, Salvador, Bahia, 63-84.

Fujimori, S. 1967. Rochas alcalinas do sul do Estado da Bahia. Notas preliminares e estudos da Divisão de Geologia e Mineralogia, Rio de Janeiro, 141:3-11.

Gomes, R.A.A.D.;Arcanjo, J.B.A.; Reginaldo, A.S. 1991. Colisão de blocos em subducção na Costa Sul da Bahia. II Intern. Congr. Brazilian Geophys. Soe., Salvador, Bahia. Extended. Abstracts., 1, 154-159.

Halls, H.C. 1982. The Importance and Potencial of Mafic Dyke Swarms in the Studies of Geodynamics Processes. Geosc. Canada, 9:145-154.

Halls, H.C. \& Fahrig, W.F. (eds), 1987. Mafic Dyke Swarms. Geol. Assoe. Canada, Special Paper, 34:503p.

Hill, R.I., 1991. Starting plumes and continental break-up. Earth Planei. Sei. Lett., 104:398-416.

Karmann, 1.1987. O Grupo Rio Pardo (Proterozóieo Médio a Superior): Uma Cobertura Para-Plataformal da Margem Sudeste do Craton do São Francisco. Instituto de Geociências, Universidade de São Paulo, São Paulo, Dissertação de Mestrado, 129p
Lima, M.I.C. de; Fonseca, E.G. da; Oliveira, E.P. de; et al. 1981. Folha SD-24 Salvador. Cap. I -Geologia. Projeto RADAMBRASIL, Brasil, Ministério das Minas e Energia. Secretaria Geral, 25-192.

Logan, J.M. \& Teufel, L.W. 1986. The effect of normal stress on the real area of contact during frictional sliding in rocks. Paleoph., 124,3:471-485.

Loureiro, H.S.C. 1991. Programa de Levantamentos Básicos do Brasil. Folha Mundo Novo.SC.24-Y-D-IV, 1:100.000, Estado da Bahia, Convénio DNPM/CPRM, 196p, 2 mapas.

Oliveira, E.P. de \& Montes, M.L. 1984. Os enxames de diques máficos do Brasil. SBG, Cong. Brás. Geol., 33, Rio de Janeiro-RJ., IX:4137-4154.

Oliveira, E P. \& Knauer, L.G. 1993. Corpos máficos e ultramáficos do Craton do São Francisco. In: Dominguez, J.M.L. \& Misi A. (eds.). Reunião Preparatória do II Simp. do Craton do São Francisco, 119-136.

Oliveira, E.P.; Tarney, J.; João, X.J. 1990. Geochemistry of the Mesozoic Amapá and Jari Dyke Swarms, Northern Brazil: plume-related magmatism during the opening of the Central Atlantic: In: Parker, A.J., Rickwood, P.C. \& Tucker, D.H. (eds.), Mafic Dykes and Emplacement Mechanisms, A.A. Balkema, Rotterdam, 173-183.

Padilha, A.V. 1992. Estruturas tectônicas da Folha SC-24-Y-D-II. In: Programa de Levantamentos Geológicos Básicos do Brasil. Gavião, Folha SC-24-Y-D-II, 1:100.000, Estado da Bahia, DNPM/CPRM, Cap. 3:51-57.

Padilha, A.V. \& Melo, R.C. 1991. Estruturas e Tectônica da Folha SC-24-Y-D-V. In: Programa de Levantamentos Geológicos Básicos do Brasil. Pintadas, Folha SC-24-Y-D-V, 1:100.000, Estado da Bahia, DNPM/CPRM, Cap. 3:49-54.

Parker, A.J.; Rickwood, P.C.; Tucker. D.H. (eds.) 1990. Mafic dykes and emplacement mechanisms. 23, Inter. Geol.Correl. Prog., Project 257, .II Inter. Dyke Conf, Adelaide / South Austrália, A.A. Balkema/ Rotterdam/ Brookfield. Publ., 506 p.

Pedreira, A.J. 1979. Possible evidence of a precambrian continental collision in the Rio Pardo Basin of Eastern Brazil. Geology, 7:445-448.

Pedrosa Soares, A.C.; Noce, C.M.; Vidal, Ph.; Monteiro, R.B.P. 1992a. Discussão sobre novo modelo tectônico para a Faixa Araçuaí - Oeste Congolesa. Rev. Esc. Minas, Ouro Preto, 45,1-2:38-40.

Pedrosa Soares, A.C.; Noce, C.M.; Vidal, Ph.; Monteiro, R.B.P. 1992b. Toward a new tectonic model for the Late Proterozoic Araçuaí: (SE Brazil)- West Congolian (SW África) Belt. Jour. of South Amer. Earth Sei., 6,1-2:33-47.

Renné, P.R.; Onstott, T.C.; D'AgrelaFilho, M.S.; Pacca, I.G.; Teixeira, W. $1990 .{ }^{40} \mathrm{Ar} /{ }^{39} \mathrm{Ar}$ dating of 1.0-1.1 Ga magnetizations from the São Francisco and Kalahari Cratons: Tectonic implications for Pan-African and Brasiliano Mobile Belts. Earth and Plan. Scien. Letters, 101,2-4:349-366.

Riedel, W. 1929. Zur mechanik geologischer Brucherscheinungen: Central bl. Mineral Geol. u. Pai, 1929B:354-368.

Sabaté, P. 1996. Estrutura e tectônica do embasamento Arqueano e Proterozóieo Inferior do Estado da Bahia. In: Barbosa, J.F.S. \& Dominguez, J.M.L. (eds.), Mapa Geológico do Estado da Bahia. Texto Explicativo., Cap. X, 199-226.

Sial, A.N.; Oliveira, E.P.; Choudhuri, A. 1987. Mafic Dyke Swarms of Brazil. In: Mafic Dyke Swarms. Geol. Assoe. Canadá, Special Paper, 34:467-481.

Silva Filho, M.A.; Mascarenhas, J.F.; Moraes Filho, O; et al. 1974. Projeto Sul da Bahia. Relatório Final.Convênio DNPM/CPRM, Salvador, CPRM, 15 vols.

Swanson, M.T. 1988. Pseudotachylite-bearing strike-slip duplex structures in the Fort Foster Britle Zone, S. Maine. Jour. Struc. Geol., 10, 8:813-823.

Tanner de Oliveira, M.A.F. 1989. O Enxame de diques máficos de Olivênça: Aspectos geoquímicos epetrogenéticos. Instituto de Geociências, Universidade de São Paulo, São Paulo, Tese de Doutoramento, vol. 1 (texto), 154 p, vol. 2, Apêndices, 159 p.

Tanner de Oliveira, M.A.F. 1996. Petrografia dos Diques Máficos. In: Corrêa Gomes, L.C.; Tanner de Oliveira, M.A.F.; Motta, A.C. \& Cruz, M.J.M. (eds.). Províncias dos Diques Máficos do Estado da Bahia. Mapa, Evolução Temporal e Estágio Atual do Conhecimento - Cap.III. Convénio SICM/SGM/PPPG/UFB A., 49-74.

Tchalenko, J.S. 1970. Similarities between shear zones of different magnitudes. Geol. Soe. Amer. Bull, 8:1625-1640.

Tchalenko, J.S. \& Ambraseys N.N. 1970. Structural analysis of the Dasht-e-Bayaz (Iran). Earthquake fractures. Geol. Soe. Amer. Bull., 81:41-60.

Teixeira, W. 1993. Avaliação do acervo de dados geocronológicos e isotópicos do Craton do São Francisco-Implicações tectônicas. In: Dominguez, J. M. L. \& Misi, A (eds.), Reunião Preparatória do II Simp. do Craton do São Francisco, 11-33.

Teixeira, W.; Kamo, S.L. \& Arcanjo; J.B.A. 1997. U-Pb zircon and baddeleyite age and tectonic interpretation of Itabuna alkaline Suite, São Francisco Craton, Brazil. Jour of South Amer. Earth Sciences, 10,1:91-98.

Vialon, P. 1979. Les déformations continues-discontinues des roches anisotropes. Ecloae geoLHelv., 72,2:531-549.

Manuscrito A-969

Recebido em 25 de marco de 1998 Revisão dos dos autores em 15 de junho de 1998
Revisão aceita em 30 de junho de 1998 